\title{
EFFECT OF GRAPHENE AND CARBON FIBER ON REPAIRING CRACK OF CONCRETE BY ELECTRODEPOSITION
}

\author{
QINGKUAN YANG, JINBANG WANG, LIANWANG YUAN, " ZONGHUI ZHOU \\ Shandong Provincial Key Laboratory of Preparation and Measurement of Building Materials, University of Jinan, \\ Jinan 250022, China \\ \#E-mail: mse_zhouzh@ujn.edu.cn
}

Submitted June 28, 2019; accepted August 21, 2019

\begin{abstract}
Keywords: Electrodeposition, Repair crack, Graphene, Carbon fiber, Sediment
For many years, researches have investigated concrete repair technologies including epoxy resin injection technology, bioremediation technology and self-healing technology. However, these repair methods have proven to be expensive and cumbersome to be carry out. A more recent technology electrochemical deposition, the focus of this paper emphases in a new way of healing concrete cracks that restores durability and mechanical strength of a concrete structure. Therefore, the emphasis of the research work reported here in is to prove the repair efficiency of the electrodeposition method by adding carbon fiber and graphene to the concrete. By analyzing the mass change of the concrete, total charge passed, crack width variation, ultrasonic waves, sediment composition and morphology, it was found that the cracks with width of 0.3-0.5 mm in samples healed within 20 days. The repair efficiency of samples mixed with carbon fiber and graphene were better than specimens without carbon fiber and graphene. Moreover, the mass increase rate of a concrete samples mixed with carbon fiber and graphene was $10.15 \%$, which is twice the mass of conventional concrete. The results of SEM and X-ray diffraction analysis showed that the samples mixed with carbon fiber and graphene produced more ZnO and that had a continuous compact structure.
\end{abstract}

\section{INTRODUCTION}

Concrete as a porous brittle material, tends inevitably develop cracks under use [1]. Moisture may carry harmful substance will invade the concretes in to the concrete through pores and micro-cracks, which will have a series of adverse effects, such as strength reduction, carbonization and steel corrosion [2]. These affect not only the appearance but also the mechanical property and durability of it [3]. As a result, concrete repair will still be required as well as the costs associated with that [4]. In order to reduce the maintenance activities of concrete facilities and spending on reconstruction, the technique to repair concrete cracks to enhance its service life was investigated.

Basically, the traditional methods for repairing concrete cracks involve structural reinforcement restoration [5, 6], surface treatment [7], crack filling [8], and self-repair [9]. Those methods have disadvantages such as high cost, complicated operation or long repair time, which often does not meet the requirements for modern multifunctional buildings. Electrochemical deposition repair technology is a new way for healing concrete [10-13]. Electrodeposition fills cracks inside the concrete and forms a protective layer on the crack face. This protective layer reduces the defects of the concrete and blocks the invasion of external liquids [14]. According to previous studies, electrochemical deposition can be accomplished by applying an electric current between the steel reinforcement in concrete structure and an electrode placed in seawater (Figure 1). Steel reinforcement inside the concrete structure was used as the cathode, and the platinum electrode was placed inside the sea-water as the anode. After applying an electric current between the anode and the cathode, the cation and the anion move toward the two electrodes in response to a potential difference. Ions undergo a range of reactions and eventually formed precipitation on the surface and in the cracks of the concrete to heal the cracks and cover the surface $[10,11,13]$.

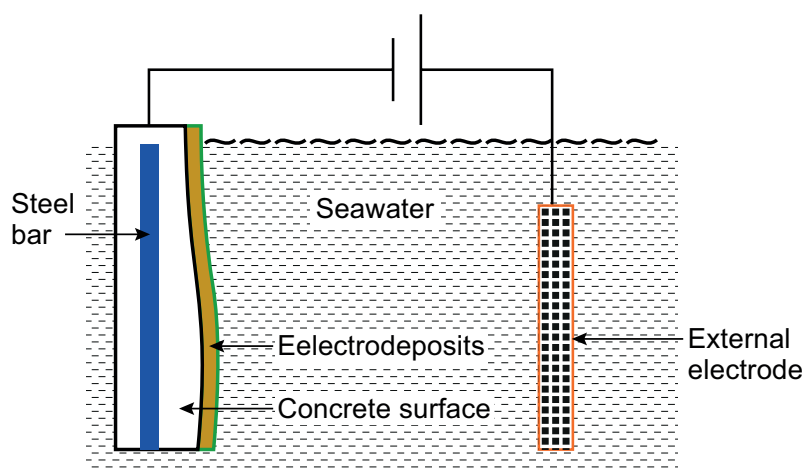

Figure 1. Application of electrodeposition in marine engineering. 
In recent years, some researchers have investigated the use of electrochemical deposition to repair cracks inside concrete structures in the marine environment. Sasaki and Yokoda et al. [15] used electrodeposition to repair marine concrete projects, which operation process was simple but recovery time was so long. Jaesuk Ryu $[10,16]$ found that electrodeposits formed on concrete surfaces sealed concrete cracks and reduced chloride ion content but the rate of repair was slow. Therefore, improving the rate of electrodeposition repair was of primary interest in this research.

Graphene and carbon fibers have excellent mechanical, electrical and thermal properties, which not only improve the physical properties and durability of concrete, but also enhances the effect of electrodeposition. The process of repairing concrete cracks by electrodeposition, it was found that the resistivity of concrete with carbon fiber and graphene was reduced $[17,18]$, thereby allowing the crack surface to manifest a greater current density. What's more, carbon fibers and graphene dispersed with ultrasonic dispersion instrument before concrete is formed, thus the exposed carbon fiber and graphene at the crack face were uniformly distributed along the fractured surface, which promoted consistency of the repair. The particles deposition models of electrodeposition are shown in Figure 2.
At present, the electrodeposition method is mainly used for metal plating, and rarely used in concrete repair. Thus, the use of electrodeposition to repair concrete cracks is still in the primary stage. Against this background, this work is devoted to studying the repair effects of graphene and carbon fiber on the effectiveness of the electrodeposition method and the associated healing mechanism.

\section{EXPERIMENTAL}

\section{Raw materials}

Test specimens were prepared using ordinary Portland cement of strength grade 42.5 produced by Shandong Shanshui Cement Group Co., Ltd. The physical properties are shown in Table 1 and the chemical compositions are shown in Table 2. The fine aggregate used in the specimens was an ISO standard sand. The carbon fiber was PAN-based chopped carbon fiber, and its physical properties are shown in Table 3. The graphene was produced by Changzhou Sixth Element Materials Technology Co., Ltd., where the physical properties are shown in Table 4, and the particle size distribution is shown in Figure 3. The particle size distribution of graphene is concentrated with particle sizes ranging from 4 to $10 \mu \mathrm{m}$, and the median diameter at $5.1 \mu \mathrm{m}$.

Table 1. Physical properties of cement.

\begin{tabular}{|c|c|c|c|c|c|c|}
\hline \multirow{2}{*}{$\begin{array}{l}\text { Initial } \\
\text { setting time } \\
\quad(\min )\end{array}$} & \multirow{2}{*}{$\begin{array}{l}\text { Final } \\
\text { setting time } \\
\quad(\min )\end{array}$} & \multirow[t]{2}{*}{ Stability } & \multicolumn{2}{|c|}{$\begin{array}{l}\text { Flexural strength } \\
\qquad(\mathrm{MPa})\end{array}$} & \multicolumn{2}{|c|}{$\begin{array}{c}\text { Compressive strength } \\
(\mathrm{MPa})\end{array}$} \\
\hline & & & $3 \mathrm{~d}$ & $28 \mathrm{~d}$ & $3 d$ & $28 \mathrm{~d}$ \\
\hline 125 & 187 & Qualified & 4.1 & 7.5 & 24.9 & 48.3 \\
\hline
\end{tabular}

Table 2. Chemical composition of cement (wt. \%).

\begin{tabular}{cccccccc}
\hline $\mathrm{SiO}_{2}$ & $\mathrm{Al}_{2} \mathrm{O}_{3}$ & $\mathrm{Fe}_{2} \mathrm{O}_{3}$ & $\mathrm{CaO}$ & $\mathrm{MgO}$ & $\mathrm{SO}_{3}$ & $\mathrm{Cl}^{-}$ & loss \\
\hline 21.45 & 5.93 & 3.45 & 60.87 & 3.12 & 2.35 & 0.027 & 2.80 \\
\hline
\end{tabular}

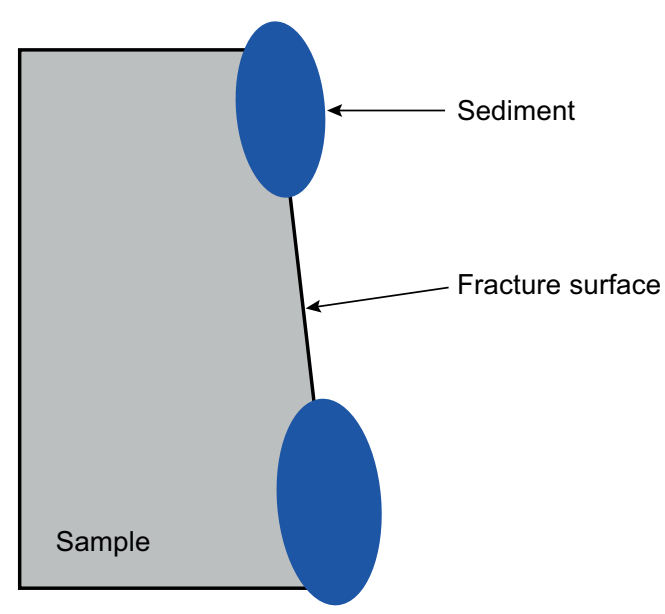

a) without carbon fiber and graphene

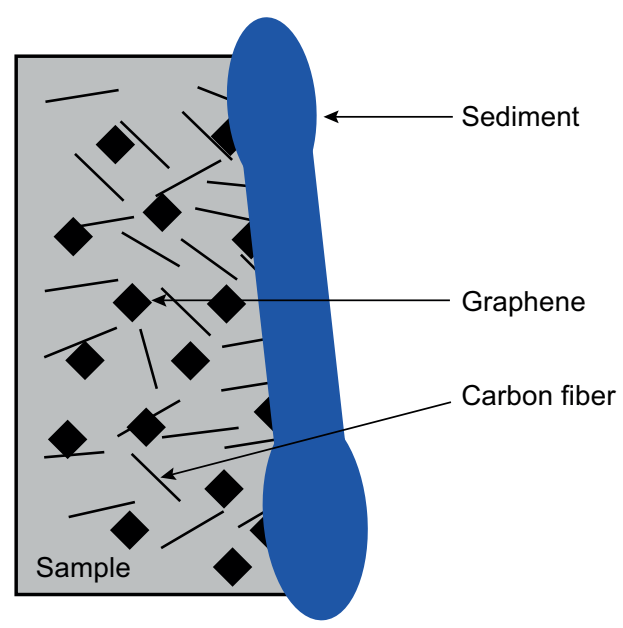

b) contains carbon fiber and graphene

Figure 2. Particles deposition model of electrodeposition. 
Effect of graphene and carbon fiber on repairing crack of concrete by electrodeposition

Table 3. Physical properties of carbon fibers.

\begin{tabular}{cccccc}
\hline $\begin{array}{c}\text { Length } \\
(\mathrm{mm})\end{array}$ & $\begin{array}{c}\text { Diameter } \\
(\mu \mathrm{m})\end{array}$ & $\begin{array}{c}\text { Density } \\
\left(\mathrm{g} \cdot \mathrm{cm}^{-3}\right)\end{array}$ & $\begin{array}{c}\text { Tensile strength } \\
(\mathrm{MPa})\end{array}$ & $\begin{array}{c}\text { Tensile modulus } \\
(\mathrm{GPa})\end{array}$ & $\begin{array}{c}\text { Resistivity } \\
(\Omega \cdot \mathrm{m})\end{array}$ \\
\hline 6 & 7 & 1.8 & 3900 & 230 & $1.5 \times 10^{-3}$ \\
\hline
\end{tabular}

Table 4. Physical properties of graphene.

\begin{tabular}{lccccc}
\hline $\begin{array}{c}\text { Diameter } \\
(\mu \mathrm{m})\end{array}$ & $\begin{array}{c}\text { Surface area } \\
\left(\mathrm{m}^{2} \cdot \mathrm{g}^{-1}\right)\end{array}$ & $\begin{array}{c}\text { Thickness } \\
(\mathrm{nm})\end{array}$ & $\begin{array}{c}\text { Purity } \\
(\%)\end{array}$ & Layers & $\begin{array}{c}\text { Electron conductivity } \\
\left(\mathrm{S} \cdot \mathrm{m}^{-1}\right)\end{array}$ \\
\hline$<10$ & $200-280$ & $<6$ & $>98$ & $<5$ & $106-107$ \\
\hline
\end{tabular}

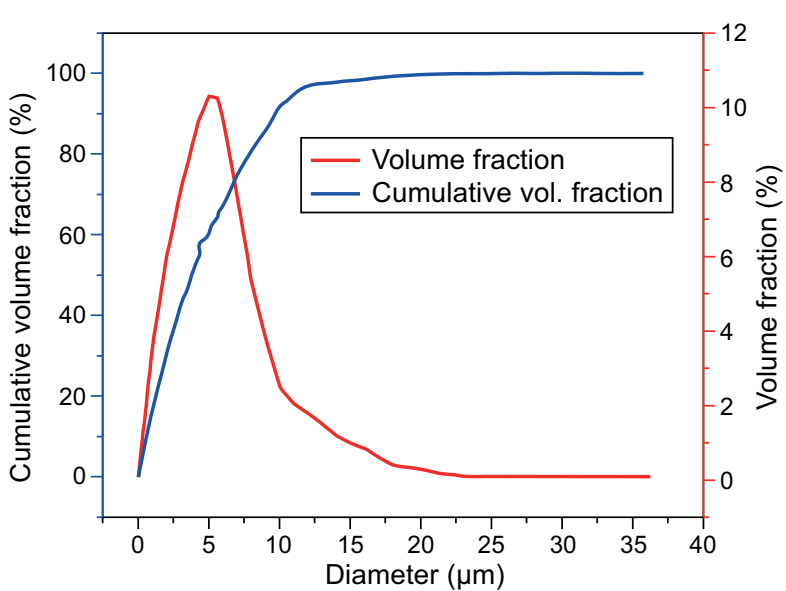

Figure 3. Particle size distribution of graphene.

\section{Test material apparatus}

The size of the samples used in the test program were $40 \times 40 \times 160 \mathrm{~mm}$ and $\Phi 100 \times 50 \mathrm{~mm}$. The water-cement ratio was 0.5 . The diameter of the steel reinforcement was $6 \mathrm{~mm}$. Curing the samples for 28 days under standard curing environment (Temperature $20 \pm 2{ }^{\circ} \mathrm{C}$, Relative Humidity $>95 \%$ ). The samples were loaded by Electronic Universal Testing Machines to produce cracks which had the width of 0.3 to $0.5 \mathrm{~mm}[19,20]$. In order to ensure the sample crack width is unchanged, except for the cracked side, the others five sides of each sample were sealed with a resin with the samples of $40 \times 40 \times 160 \mathrm{~mm}$, and the flanks of the samples of $\Phi 100 \times 50 \mathrm{~mm}$ was also wrapped with a resin. The electrolyte solution was a mixture of $\mathrm{ZnSO}_{4}$ solution and absolute ethanol. The concentration of $\mathrm{ZnSO}_{4}$ solution was $0.05 \mathrm{~mol} \cdot \mathrm{l}^{-1}$, and the volume fraction of anhydrous ethanol was $25 \%$. Anhydrous ethanol was an additive,

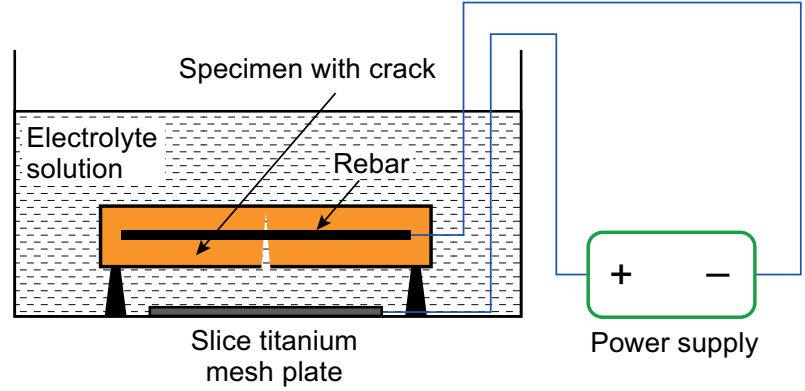

Figure 4. Schematic diagram of the experimental device.

which weakens the hydrogen evolution reaction in the electrolyte solution [21, 22], and maximizes the deposition of $\mathrm{ZnO}$ while ensuring a certain amount of $\mathrm{OH}^{-}$. The concentration of the electrolyte solution should be kept stable in order to reduce the experimental error, so the electrolyte solution was changed every 5 days. Powered by a direct current regulated power supply for 20 days, and the voltage was stabilized at 5 volts, which is much lower than the human body safety voltage and provides a certain current density. The experimental setup and mixing ratio are shown in Figure 4 and Table 5 respectively.

\section{Mass change test}

Electronic balance with $0.01 \mathrm{~g}$ precision is shown in Figure 5a. After pre-cracking, the sample was weighed $M_{0}$. After applying electric current for 5 days, the sample was taken out from electrolyte solution and dried for 24 hours, then the mass the sample was weighed $M_{\mathrm{i}}$. The mass change of the sample was: $R_{\mathrm{m}}=M_{\mathrm{i}}-M_{0}$. The sample was weighed every 5 days.

Table 5. Mixing ratio of the mortar samples.

\begin{tabular}{ccccccc}
\hline $\begin{array}{c}\text { Serial } \\
\text { number }\end{array}$ & $\begin{array}{c}\text { Cement } \\
(\mathrm{g})\end{array}$ & $\begin{array}{c}\text { Water } \\
(\mathrm{g})\end{array}$ & $\begin{array}{c}\text { Standard sand } \\
(\mathrm{g})\end{array}$ & $\begin{array}{c}\text { Graphene } \\
(\mathrm{g})\end{array}$ & $\begin{array}{c}\text { Carbon fiber } \\
(\mathrm{g})\end{array}$ & $\begin{array}{c}\text { Ultrasonic time } \\
(\mathrm{min})\end{array}$ \\
\hline Control & 450 & 225 & 1350 & 0 & 0 & 30 \\
GM & 450 & 225 & 1350 & 0.45 & 0 & 30 \\
CM & 450 & 225 & 1350 & 0 & 3.6 & 30 \\
GCM & 450 & 225 & 1350 & 0.45 & 3.6 & 30 \\
\hline
\end{tabular}




\section{RCPT Method}

Rapid Chloride ion Penetrability Test (RCPT) was implemented on the basis of the requirements of ASTM C1202-97 [23]. $\Phi 100 \times 50 \mathrm{~mm}$ sample was processed with a vacuum saturation apparatus and then placed in a standard fixture. The solutions placed in standard fixture was sodium hydroxide solution at a concentration of $0.3 \mathrm{~mol} \cdot \mathrm{l}^{-1}$ and sodium chloride solution with a mass fraction of $3 \%$ respectively. The positive and negative ions migrate under the action of electric field when $60 \mathrm{~V}$ direct current was applied to the sample. The impermeability of the concrete was reflected according to the total charge passed in 6 hours. The experimental device is shown in Figure 5b.

\section{Crack width measurement}

The width of cracking was measured using the intelligent crack width meter [24], which measurement range is 0 to $4 \mathrm{~mm}$ with an accuracy of $0.01 \mathrm{~mm}$. When the probe was aimed at the crack, the magnified crack image could be seen on the LCD screen. Fine-tune probe to make the image clear and save it. The experimental device is shown in Figure 5c.

\section{Ultrasonic testing}

The change of ultrasonic wave can reflect the internal defects a concrete specimen $[25,26]$. Tektronix AFG3022B arbitrary waveform generator and Tektronix

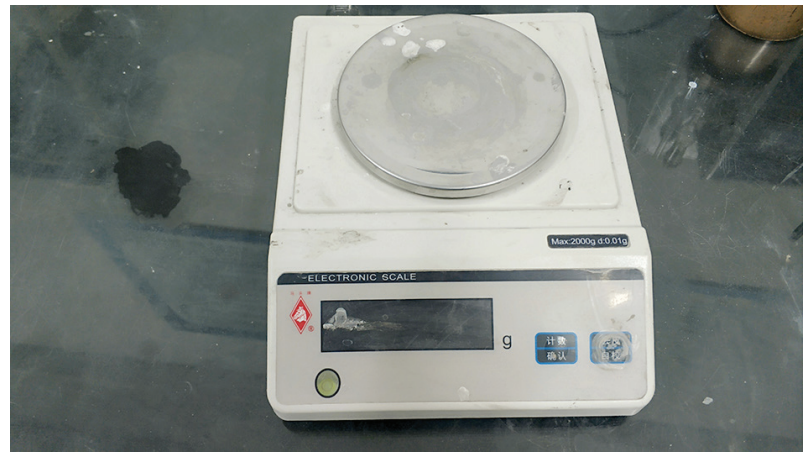

a) electronic balance

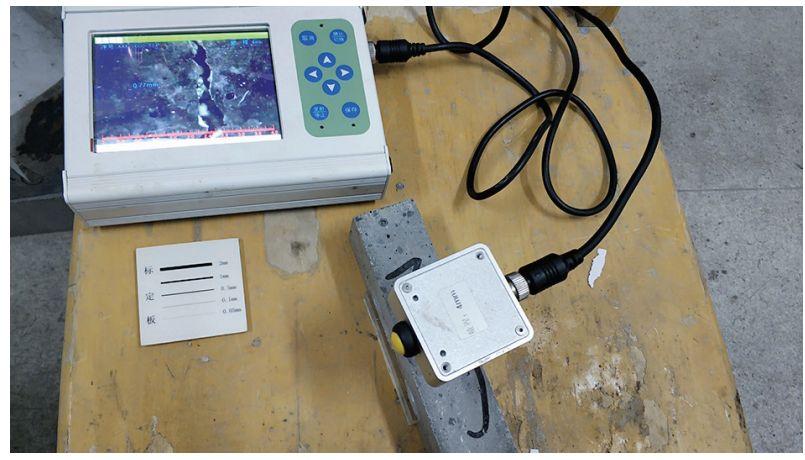

c) crack width meter
TDS1002B-SC was used as the digital oscilloscope in this testing. The ultrasonic frequency was $50 \mathrm{kHz}$ and the input voltage $10 \mathrm{~V}$. The amplitude values, transmitting times, and waveform of the ultrasonic was recorded. The experimental device is shown in Figure 5d.

\section{RESULTS AND DISCUSSIONS}

Mass change analysis

Figure 6 shows the mass change of the different samples after applying the electric current for 20 days.

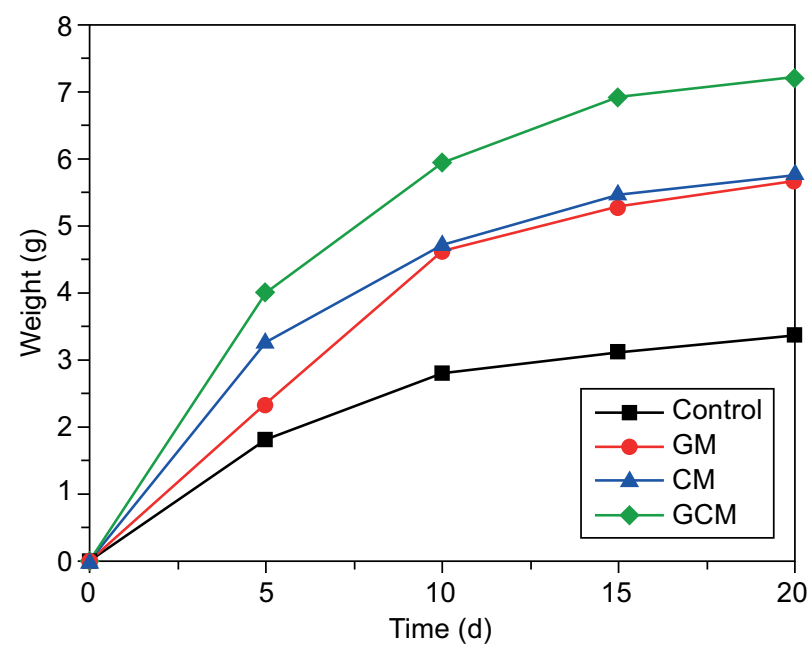

Figure 6. Mass change of sample.

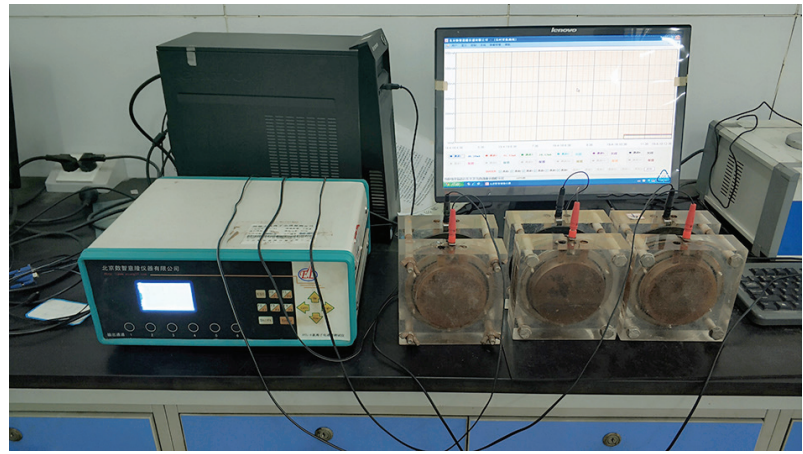

b) RCPT instrument

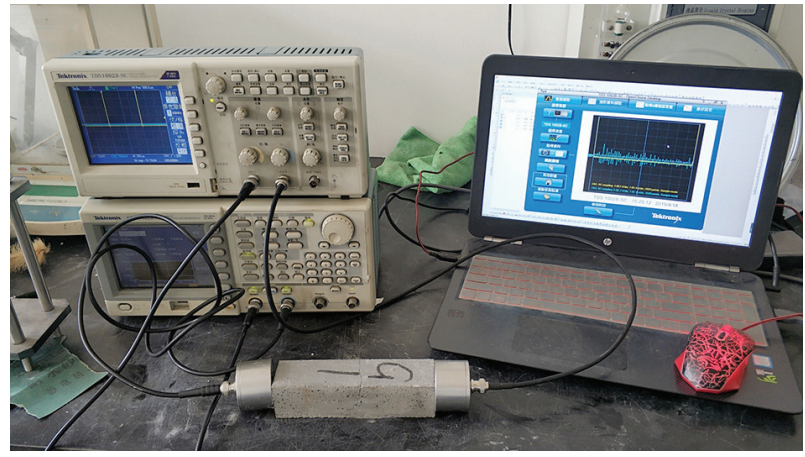

d) ultrasonic instrument

Figure 5. Main experimental devices. 
The mass of the Control sample increased by $3.36 \mathrm{~g}$, GM by $5.67 \mathrm{~g}, \mathrm{CM}$ by $5.75 \mathrm{~g}$, and GCM by $7.22 \mathrm{~g}$. The mass increase of GM, CM and GCM increased by $68.8 \%, 71.1 \%$ and $114.9 \%$, respectively, compared with the Control sample. This is due to the samples with graphene and carbon fiber give mortar a smaller resistivity, therefore the surface of the crack has a larger current density, which leads to more sediments were generated. Moreover, the exposed graphene and carbon fibers on the fracture surface increase the surface area of the fracture, which making sediment easier to deposit on the fracture surface. The chemical reactions in the electrolyte solution are shown in Table 6.

Table 6. Chemical reactions in the electrolyte solution.

\begin{tabular}{lr}
\hline $\mathrm{H}_{2} \mathrm{O} \rightarrow 1 / 2 \mathrm{O}_{2} \uparrow+2 \mathrm{H}^{+}+2 \mathrm{e}^{-}$ & $\begin{array}{r}\text { (anode) } \\
2 \mathrm{H}_{2} \mathrm{O}+2 \mathrm{e}^{-} \rightarrow \mathrm{H}_{2} \uparrow+2 \mathrm{OH}^{-}\end{array}$ \\
\hline $\mathrm{H}_{2} \mathrm{O} \rightarrow 2 \mathrm{OH}^{-}+2 \mathrm{H}^{+}$ & (cathode) \\
$\mathrm{Zn}^{2+}+2 \mathrm{OH}^{-} \rightarrow \mathrm{ZnO} \downarrow+\mathrm{H}_{2} \mathrm{O}$ & (Aqueous reaction) \\
\hline
\end{tabular}

\section{RCPT analysis}

Figure 7 shows the total charge passed in 6 hours through each sample after repaired for 20 days. The total charge passed of the Control sample, GM, CM and GCM were 3491 coulombs, 1840 coulombs, 1529 coulombs and 894 coulombs respectively. The total charge passed of GM sample, CM and GCM were reduced by $47.3 \%, 56.2 \%$ and $74.4 \%$, respectively, compared with that of Control sample. GCM has the smallest total charge passed and the best resistance to chloride ion permeation. Depending on the mass change, the GCM sample produced more sediment. Besides that, the uniform distribution of graphene and carbon fiber at the crack resulted in greater uniformity of the sediment.
A characteristic of the repair was a decrease in total charge passed and an increase in impermeability of the mortar.

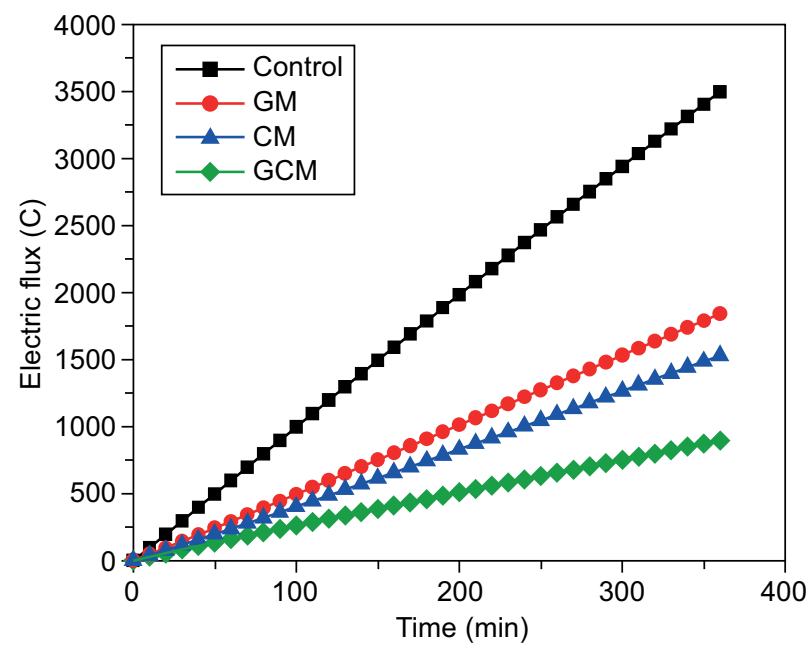

Figure 7. The total charge passed of the sample.

\section{Analysis of crack microscopic images}

Figure 8 shows the microscopic images of cracks in four samples at different healing times. It was noted that the width of the cracks ranged from $0.3-0.5 \mathrm{~mm}$ in the stages of pre-cracked, and white sediment was generated after the electric current was applied. This white sediment filled the cracks and formed a protective layer on the surface of the sample. After applying the electric current during 20 days, the cracks of all the samples were completely healed. The cracks of the Control sample healed slowly, and there are still obvious cracks on the $15^{\text {th }}$ day. The GM sample and CM healed

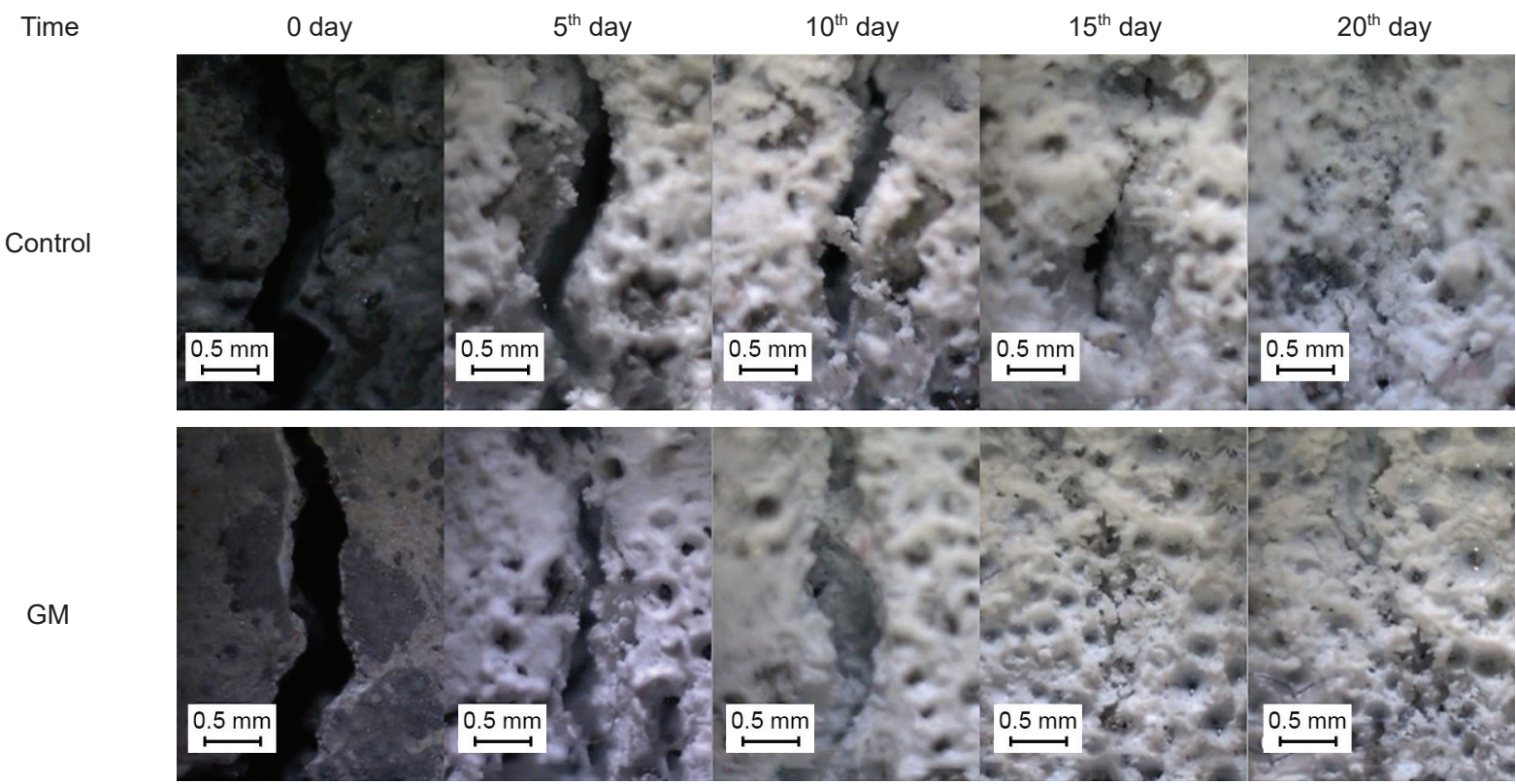

Figure 8. Crack microscopic image of the sample. (Continue on next page) 
Yang Q., Wang J., Yuan L., Zhou Z.

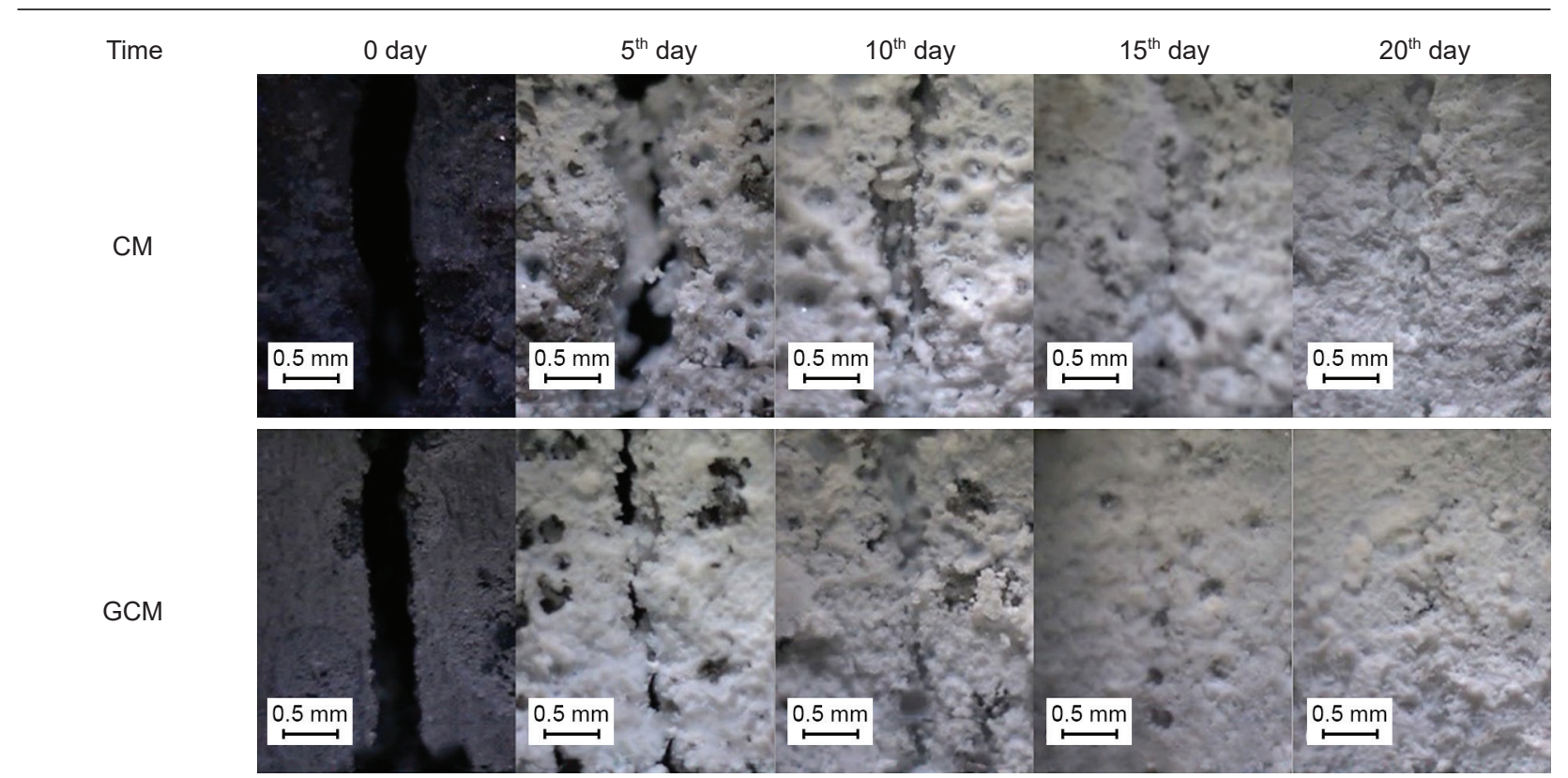

Figure 8. Crack microscopic image of the sample.

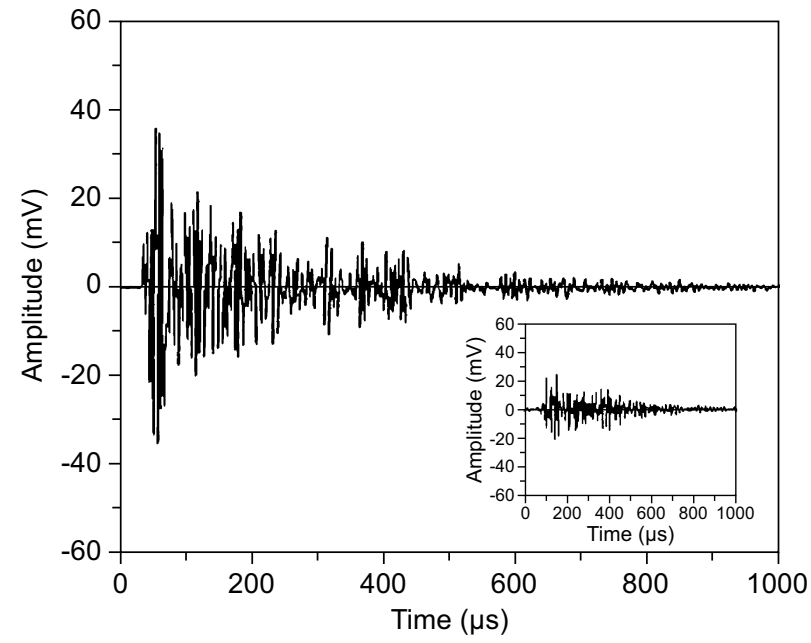

a) Control

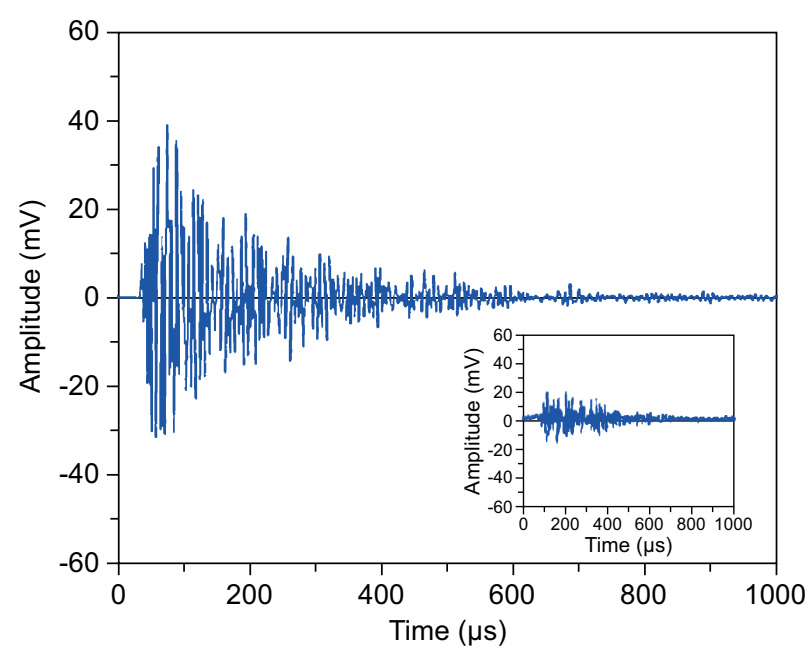

c) $\mathrm{CM}$

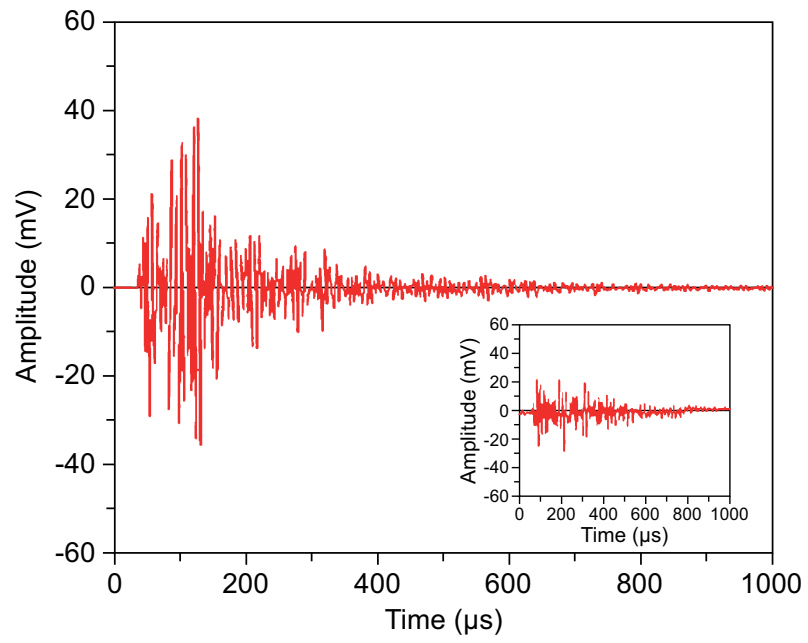

b) GM

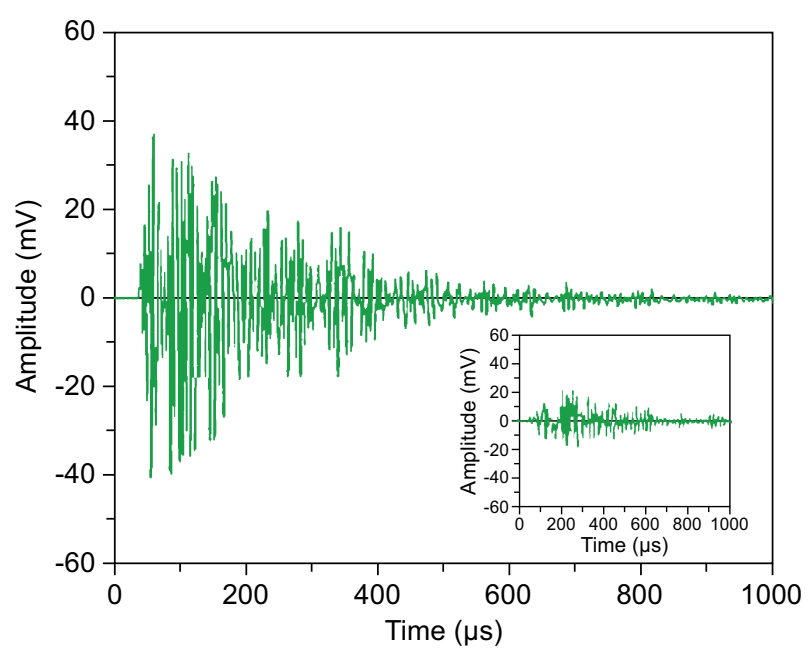

d) GCM

Figure 9. Ultrasonic waveforms before and after the test piece is destroyed. 
slightly faster than Control one, and the crack healed well on $15^{\text {th }}$ day with only slight cracking. The best repair was GCM sample, which was completely healed in $15^{\text {th }}$ days. The law of crack healing is consistent with the law of mass change and the law of anti-permeability.

\section{Ultrasonic analysis}

When concrete cracks are generated, some features of the crack can be expressed by the waveform changes, amplitude value and the transmitting time of ultrasonic wave $[27,28]$. Figure 9 displays representative ultrasonic waveforms for the Control sample, GM, CM and GCM obtained in the stages of pre-cracked (small picture) and healed for 20 days (large picture) respectively. The transmitting time and amplitude values were acquired from the head wave of the ultrasonic waveform. When these samples get cracked, the transmitting times of Control sample, GM, CM, and GCM were $66.9 \mu \mathrm{s}$,

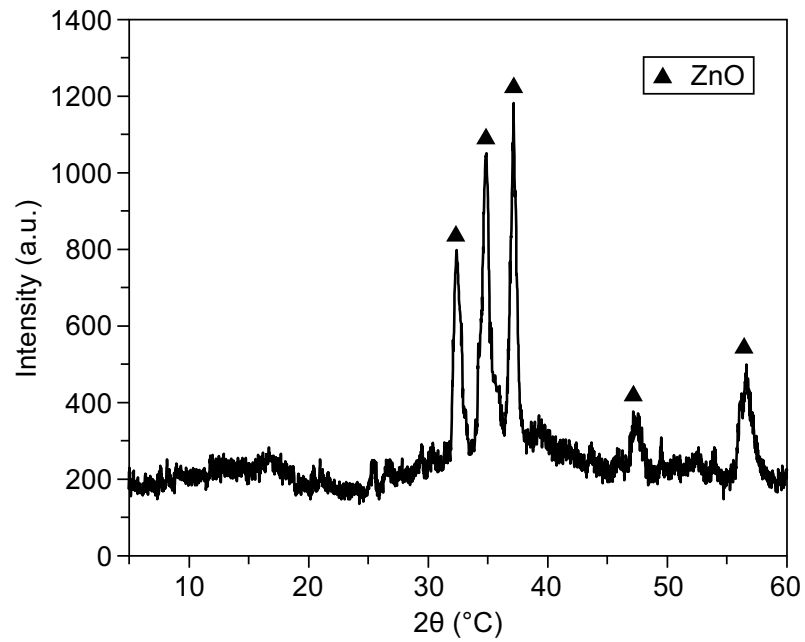

a) Control

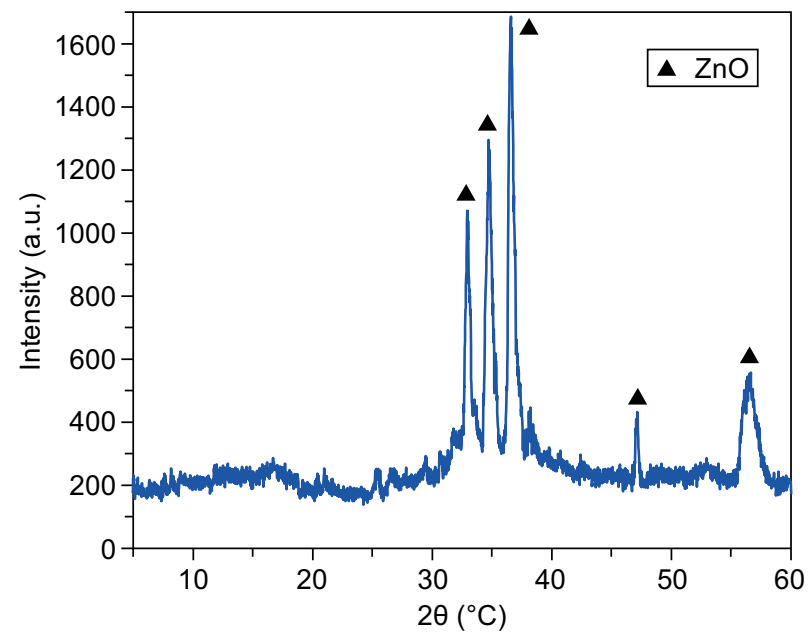

c) $\mathrm{CM}$
$63.4 \mu \mathrm{s}, 69.1 \mu \mathrm{s}$, and $67.8 \mu \mathrm{s}$, respectively, and the amplitude values were $2.8 \mathrm{mV}, 3.1 \mathrm{mV}, 2.5 \mathrm{mV}$, and $2.7 \mathrm{mV}$, respectively. This is due to the crack that has a strong interference with the propagation of the ultrasonic wave, which lead to ultrasonic with a large transmitting time, small amplitude values, and unstable waveform. After 20 days of repairing, the transmitting times of Control sample, GM, CM and GCM were reduced to $53.4 \mu \mathrm{s}, 46.5 \mu \mathrm{s}, 44.8 \mu \mathrm{s}$ and $40.7 \mu \mathrm{s}$, respectively, and the amplitudes values increase to $5.1 \mathrm{mV}, 6.5 \mathrm{mV}$, $6.9 \mathrm{mV}$ and $7.3 \mathrm{mV}$, respectively. The defection inside the samples were obviously reduced and the cracks repaired, so that the transmitting times of the ultrasonic wave was reduced and the amplitude values increased. The GCM sample has the smallest transmitting time and the largest amplitude value, which indicates that the defects inside the GCM sample was the least, and the repair effect was better than the Control sample, GM and CM.

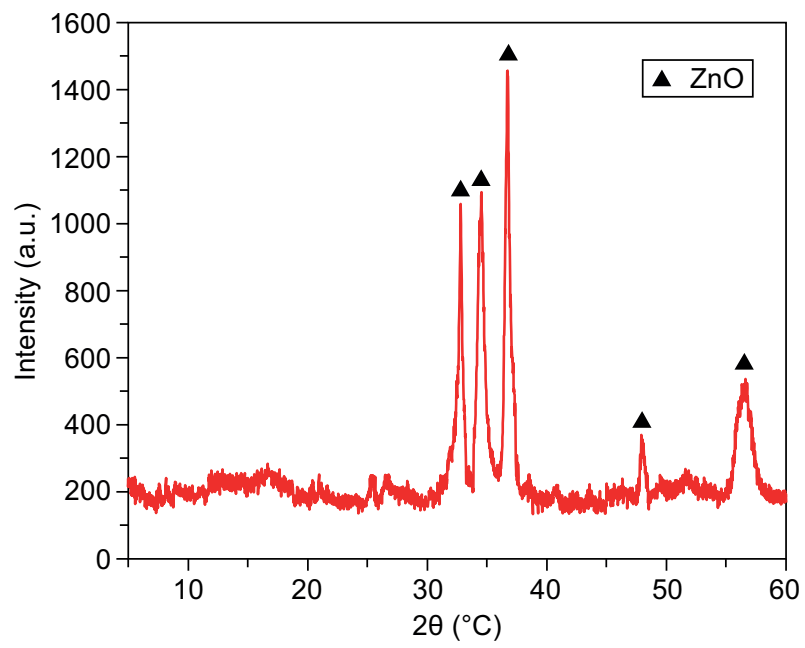

b) $\mathrm{GM}$

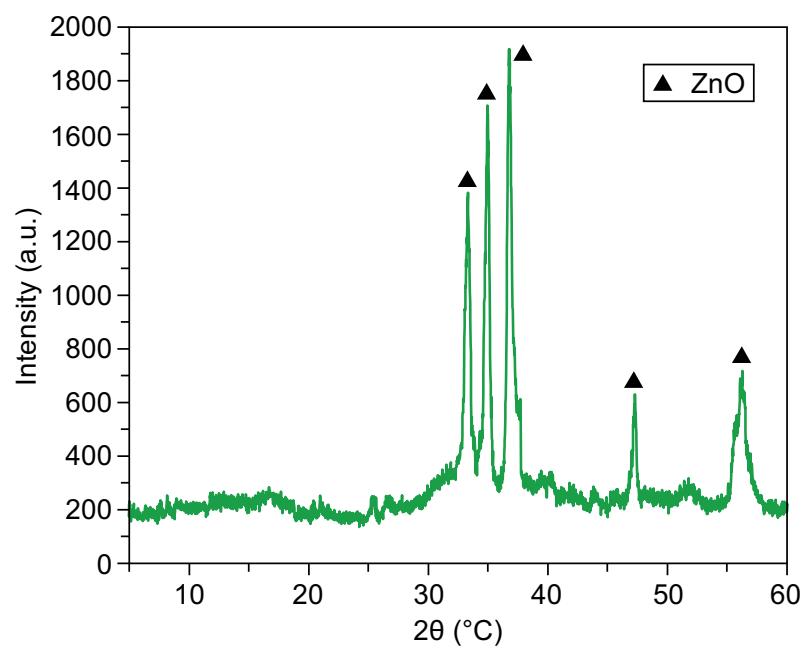

d) $\mathrm{GCM}$

Figure 10. XRD spectrums of the white sediments inside the cracks. 


\section{X-ray diffraction analysis}

The XRD spectrums of the white sediments formed on the cracks of the samples after repaired 20 days as shown in Figure 10. Comparing Figure 10 with the JCPDS card, the spectrum on the surface of the diffractive crystal corresponds to the standard diffraction peak of $\mathrm{ZnO}$, and there are extremely few impurity peaks, which indicated that the sediments produced by electrolytic deposition are $\mathrm{ZnO}$ crystal with higher purity and graphene and carbon fiber are not affecting the composition of the sediments. Narrow and sharp diffraction peaks shape were found in XRD spectrums of all the samples, which proved that the $\mathrm{ZnO}$ crystals generated have larger size and good crystallinity. At the diffraction angles of $32^{\circ}, 34^{\circ}$, and $37^{\circ}$, the intensity of the diffraction peak of GCM sample was higher than that of other samples, which demonstrated that the $\mathrm{ZnO}$ crystal formed in GCM samples is more than the $\mathrm{ZnO}$ crystal formed in other samples.

\section{Scanning electron microscopy analysis}

The SEM images of the sediments inside the cracks are shown in Figure 11. It can be seen from the figure that the morphology of the $\mathrm{ZnO}$ crystal changes

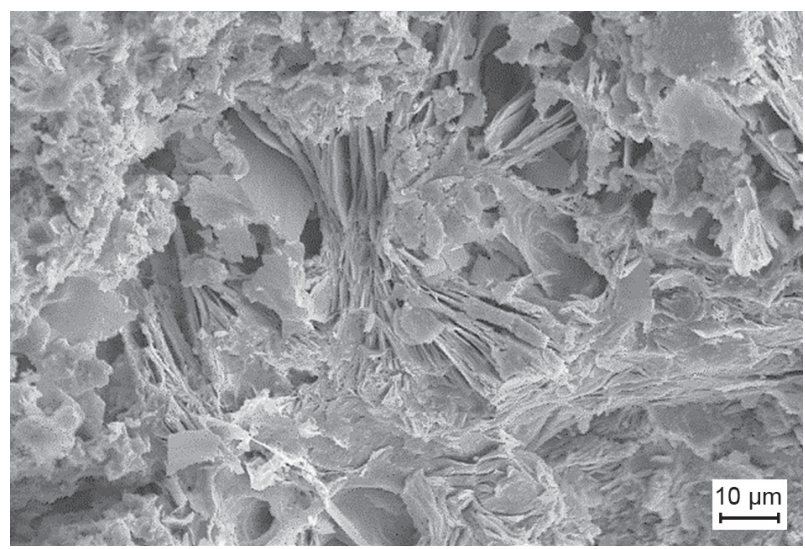

a) Control

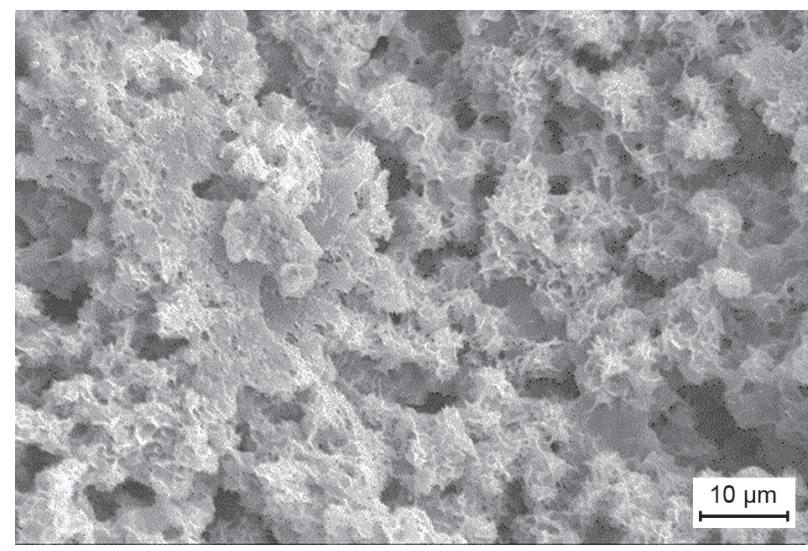

c) $\mathrm{CM}$ with the composition of the mortar. Most of the $\mathrm{ZnO}$ crystals inside the crack of Control sample are slicelike structures, which are loosely arranged and have no regularity causes poor impermeability and strength of concrete. Most of the $\mathrm{ZnO}$ crystals in GM sample presented grain-shaped. There are numerous flowerlike $\mathrm{ZnO}$ crystals in the $\mathrm{CM}$ sample, and these crystals have a certain continuity. The $\mathrm{ZnO}$ crystals in the GCM sample was closely intertwined to form a continuous structure with less pores, which owing to the uniform distribution of exposed carbon fiber and graphene on the fracture surface increased the contact area between electrolyte solution and sample. As consequences $\mathrm{ZnO}$ crystals grown uniformly on the surface of the crack to form a uniform and compact structure, thereby the mortar strength improved and the permeability reduced.

\section{CONCLUSION}

In this paper, the electrolytic deposition effects of different components of the concrete was studied, and the mechanism of electrolytic deposition to repair concrete cracks was also discussed. Based on the results achieved in this research, this thesis gets the following conclusion:

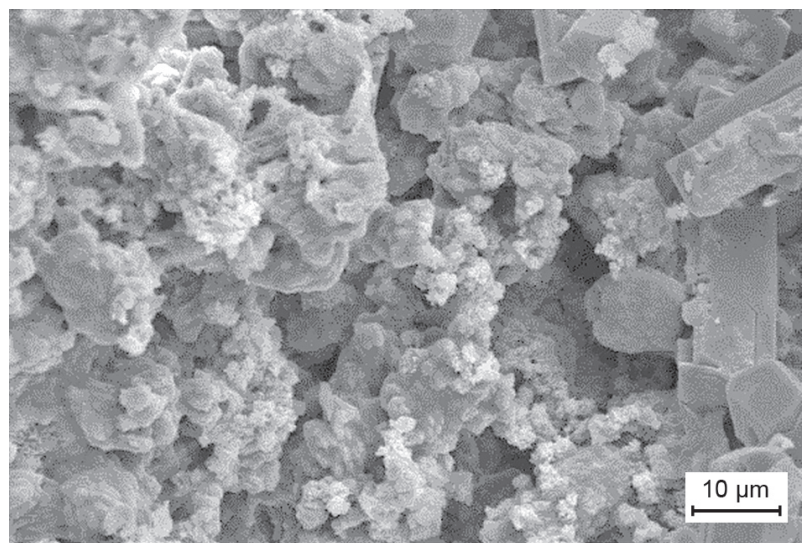

b) GM

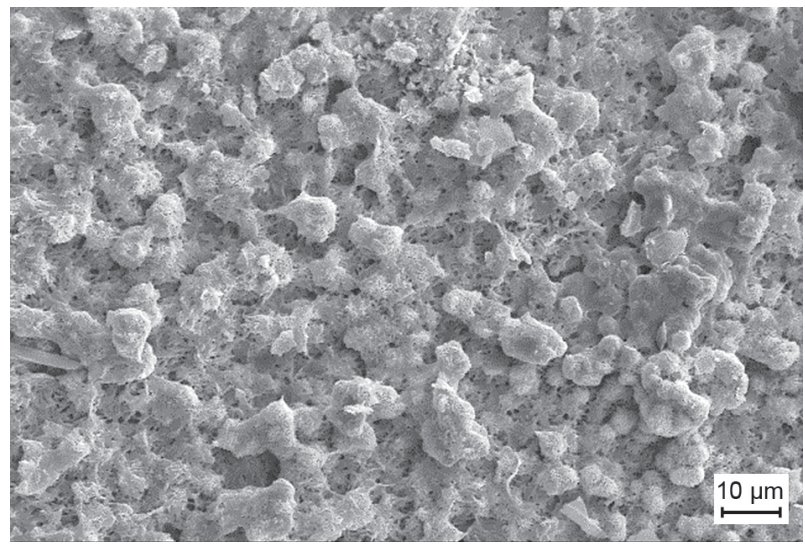

d) GCM

Figure 11. SEM images of sediments inside the cracks. 
- After the application of electric current, the crack was eventually healed regardless the composition of the mortar, and the repairing speed of cracks was the maximum in the first 5 days.

- After applied electric current for 20 days, the mass of the GCM sample increased by $7.22 \mathrm{~g}$ (114.9\% relative to the Control sample) and the total charge passed was 894 coulombs (reduced by $74.4 \%$ relative to the Control sample). With the resistance to chloride ion penetration: Control sample $<\mathrm{GM}<\mathrm{CM}<\mathrm{GCM}$.

- Ultrasonic diagrams analysis shows that the transmitting time, amplitude value and waveform of Control sample, GM, CM and GCM are mainly affected by cracks. The crack width of all samples is close after pre-cracking, therefore the difference was not large. After repairing 20 days, the transmitting times of the samples decreased and the amplitude value increased, suggesting that the cracks of the samples has been repaired to some extent. GCM has the best repair effect, the transmitting time is reduced from $67.8 \mu \mathrm{s}$ to $40.7 \mu \mathrm{s}$, and the amplitude is increased from $2.7 \mathrm{mV}$ to $7.3 \mathrm{mV}$ (increased by $170.4 \%$ ).

- Control sample contains numerous slice-like $\mathrm{ZnO}$ crystals, which are arranged loosely and have no regularity results in weak impermeability and mechanical properties. Most of the $\mathrm{ZnO}$ crystals in GM presented grain-shaped. Flower-like $\mathrm{ZnO}$ with a certain continuity in CM, improving the impermeability and mechanical properties. The $\mathrm{ZnO}$ crystals in the GCM samples are intertwined to form a uniform and compact structure, which leads to a good macroscopic performance of concrete.

\section{Acknowledgements}

Authors appreciate the financially supported from National Key Research and Development Program of China (2017YFB0309905), National Natural Science Foundation of China (No.51872120), 111 Project of International Corporation on Advanced Cement-based Materials (No. D17001).

\section{REFERENCES}

1. Grassl P., Johansson M., Leppänen J. (2018): On the numerical modelling of bond for the failure analysis of reinforced concrete. Engineering Fracture Mechanics, 189, 13-26. doi: 10.1016/j.engfracmech.2017.10.008

2. Shalaby H. M, Daoud O. K. (1990): Case studies of deterioration of coastal concrete structures in two oil refineries in the arabian gulf region. Cement \& Concrete Research, 20(6), 975-985. doi: 10.1016/0008-8846(90)90061-2

3. Subathra Devi V. (2018): Durability properties of multiple blended concrete. Construction and Building Materials, 179, 649-660. doi: 10.1016/j.conbuildmat.2018.05.056
4. Herrmann, Andrew W. (2013): Asce 2013 report card for americal"s infrastructure. IABSE Symposium Report, 99(33), 9-10. doi: 10.2749/222137813806368343

5. Mechtcherine, Viktor. (2013): Novel cement-based composites for the strengthening and repair of concrete structures. Construction and Building Materials, 41, 365-373. doi: 10.1016/j.conbuildmat.2012.11.117

6. Liu H. J, Li H. M, He J. (2011): Typical seismic damage analysis and repair reinforcement methods study of reinforced concrete industrial buildings. Advanced Materials Research, 255-260, 2399-2403. doi: 10.4028/www.scientific.net/AMR.255-260.2399

7. Courard L., Piotrowski T., Garbacz A. (2014): Near-tosurface properties affecting bond strength in concrete repair. Cement and Concrete Composites, 46, 73-80. doi: 10.1016/j.cemconcomp.2013.11.005

8. Cai H., Li Y., Li R. (2011): Experimental research on new and old crack comprehensive repair to concrete beams. International Conference on Consumer Electronics, 2011, 1264-1267. doi: 10.1109/CECNET.2011.5769213

9. Schlangen E., Sangadji S. (2013): Addressing infrastructure durability and sustainability by self healing mechanisms - recent advances in self healing concrete and asphalt. Procedia Engineering, 54, 39-57. doi: 10.1016/j. proeng.2013.03.005

10. Ryu J. S., Otsuki N. (2002): Crack closure of reinforced concrete by electrodeposition technique. Cement \& Concrete Research, 32(1), 159-164. doi: 10.1016/S0008-8846 (01)00650-0

11. Ryou J. S., Otsuki N. (2005): Experimental study on repair of concrete structural members by electrochemical method. Scripta Materialia, 52(11), 1123-1127. doi: 10.1016/ j.scriptamat.2005.02.001

12. Vaidya S., Allouche E. N. (2010): Electrokinetically deposited coating for increasing the service life of partially deteriorated concrete sewers. Construction and Building Materials, 24(11), 2164-2170. doi: 10.1016/j.conbuildmat. 2010.04.042

13. Chu H., Jiang L., Xiong C., You L., Xu N. (2014): Use of electrochemical method for repair of concrete cracks. Construction and Building Materials, 73, 58-66. doi: 10.1016/ j.conbuildmat.2014.09.031

14. Ryu J. S. (2001): An experimental study on the repair of concrete crack by electrochemical technique. Materials and Structures, 34(7), 433-437. doi: 10.1007/BF02482290

15. Sasaki H., Fukute T., Yokoda M. (1992): Repair method of marine reinforced concrete by electrodeposition technique. Proceedings of Annual Conference of JCI, 14, 849-854.

16. Ryu J. S. (2003): Influence of crack width, cover depth, water, cement ratio and temperature on the formation of electrodeposits on the concrete surface. Magazine of Concrete Research, 55, 35-40. doi: 10.1680/macr.2003. 55.1 .35

17. Lavagna L., Musso S., Ferro G., Pavese M. (2018): Cement-based composites containing functionalized carbon fibers. Cement and Concrete Composites, 88, 165-171. doi: 10.1016/j.cemconcomp.2018.02.007

18. Tong T., Fan Z., Liu Q., Wang S., Tan S., Yu Q. (2016): Investigation of the effects of graphene and graphene oxide nanoplatelets on the micro- and macro-properties of cementitious materials. Construction and Building Materials, 106, 102-114. doi: 10.1016/j.conbuildmat.2015. 12.092 
19. Yang S., Zollinger D. (1996): Variable-notch one-size test method for fracture energy and process zone length. Engineering Fracture Mechanics, 55(3), 383-404. doi: 10.1016/0013-7944(96)00030-6

20. García Calvo J.L., Pérez G., Carballosa P., Erkizia E., Gaitero J. J., Guerrero A. (2017): Development of ultrahigh performance concretes with self-healing micro/ /nano-additions. Construction and Building Materials, 138, 306-315. doi: 10.1016/j.conbuildmat.2017.02.015

21. Farinazzo Bergamo Dias Martins P., Papa Lopes P., Ticianelli E. A., Stamenkovic V.R., Markovic N. M., Strmenik D. (2017): Hydrogen evolution reaction on copper: Promoting water dissociation by tuning the surface oxophilicity. Electrochemistry Communications, 100, 30-33. doi: 10.1016/j.elecom.2019.01.006

22. Som N. N., Mankad V., Jha P. K. (2017): Hydrogen evolution reaction: The role of arsenene nanosheet and dopant. International Journal of Hydrogen Energy, 43, 21634-21641. doi: 10.1016/j.ijhydene.2018.03.066

23. Joshi R. (2000). Reexamination of ASTM C 1202 standard test method for electrical indication of concrete's ability to resist chloride ion penetration. Journal of Testing \& Evaluation, 28(1), 1-3. doi: 10.1520/JTE12075J
24. Ling H., Qian C. (2017): Effects of self-healing cracks in bacterial concrete on the transmission of chloride during electromigration. Construction and Building Materials, 144, 406-411. Doi:10.1016/j.conbuildmat.2017.02.160

25. Pal Kaur N., Kumar Shah J., Majhi S., Mukherjee A. (2017): Healing and simultaneous ultrasonic monitoring of cracks in concrete. Materials Today Communications, 18, 87-99. doi: 10.1016/j.mtcomm.2018.10.022

26. Zhao M., Nie Z., Wang K., Liu P., Zhang, X. (2019): Nonlinear ultrasonic test of concrete cubes with induced crack. Ultrasonics, 97, 1-10. doi: 10.1016/j.ultras.2019.04.002

27. Quiviger A., Payan C, Chaix J. F, Garnier V, Salin J. (2012): Effect of the presence and size of a real macro-crack on diffuse ultrasound in concrete. NDT\&E International, 45(1), 128-132. doi: 10.1016/j.ndteint.2011.09.010

28. Hilloulin B., Zhang Y., Abraham O., Loukili A., Grondin F., Durand O., Tournat V. (2014): Small crack detection in cementitious materials using nonlinear coda wave modulation. NDT \& E International, 68, 98-104. doi: 10.1016/ j.ndteint.2014.08.010 